\title{
Estudo longitudinal da mastite subclínica e produção de leite em um rebanho mestiço Holandês-Zebu criado em sistema semi-intensivo
}

\author{
[Longitudinal study of subclinical mastitis and milk production on crossbred Holstein x Zebu \\ cattle, housed in a semi-intensive system] \\ H.N. Costa, L.R. Molina*, E.J. Facury Filho, G.H.F.A. Moreira, A.U. Carvalho \\ Escola de Veterinária - Universidade Federal de Minas Gerais - UFMG - Belo Horizonte, MG
}

\begin{abstract}
RESUMO
Acompanhou-se durante 15 meses um rebanho leiteiro, composto por diferentes graus de sangue Holandês-Zebu (HZ), em sistema semi-intensivo. Objetivou-se avaliar o comportamento longitudinal da contagem de células somáticas (CCS) e a influência da mastite subclínica (MS) na produção total e no pico de produção de leite de vacas mestiças HZ. Inicialmente, coletaram-se amostras de leite individual para análise microbiológica, a fim de identificar o perfil de patógenos causadores de mastite. Realizou-se mensalmente a CCS com o intuito de monitorar a MS. Semanalmente, avaliou-se a produção de leite. Para avaliar o efeito da CCS sobre a produção de leite, as vacas foram divididas em dois grupos, $<200.000$ e $\geq 200.000$ células $/ \mathrm{mL}$. Os patógenos encontrados foram Streptococcus ambientais (34\%), células leveduriformes (29\%), Staphylococcus coagulase negativa (31\%) e Staphylococcus aureus (6\%), com CCS de 1.100.000, 845.000, 275.000 e 620.000, respectivamente. A CCS média variou de 255.000 a 975.000 cél. $/ \mathrm{mL}$, com prevalência média de $42 \%$ de MS. Vacas primíparas com MS apresentaram redução da produção total de leite quando comparadas às primíparas sem MS $(\mathrm{P}<0,05)$. Em contraste, a produção total das vacas multíparas não foi alterada. Não foram observadas diferenças entre a CCS, a produção total e o pico de produção nos diferentes graus de sangue HZ $(\mathrm{P}>0,05)$. A CCS das vacas diferiu $(\mathrm{P}<0,01)$ entre a secagem e o pós-parto imediato. A manutenção das condições de elevado risco ambiental em rebanho leiteiro manejado em sistema semi-intensivo pode minimizar as variações na ocorrência de MS nos períodos de verão e inverno, possibilitando a expressão do problema em vacas de diferentes graus de sangue HZ. Em um rebanho caracterizado pela ocorrência de mastite predominantemente ambiental, a produção de leite na lactação total de vacas primíparas com CCS superior a 200.000 cél./mL é reduzida em comparação com vacas com CCS inferior a 200.000 cél. $/ \mathrm{mL}$, o que não foi observado em vacas multíparas.
\end{abstract}

Palavras-chave: contagem de células somáticas, mastite ambiental, Girolando, gado de leite

\begin{abstract}
A herd of dairy cattle with different crossbreeding Holstein $x$ Zebu (HZ), housed in a semi-intensive production system, was monitored for 15 months. We aimed to evaluate the longitudinal behavior of somatic cell count (SCC) and the influence of subclinical mastitis (SM) on the milk yield and on the peak yield of crossbred HZ dairy cows. Initially, individual milk samples were collected for microbiological analysis for identification of mastitis pathogens. The SCC was performed monthly to monitor subclinical mastitis. Additionally, milk production was evaluated weekly. To evaluate the effects of SCC on milk production, the cows were identified as falling into two groups: $<200.000$ and $\geq 200.000$ cells $/ \mathrm{mL}$. The isolated pathogens were environmental streptococci (34\%), yeasts cells (29\%), coagulase-negative staphylococci (31\%) and Staphylococcus aureus (6\%). The SCC associated to each type of pathogen was $1100.000,845.000,275.000$ and 620.000, respectively. The average SCC varied from 255.000 to 975.000 cells $/ \mathrm{mL}$ and the prevalence of $S M$ was $42 \%$. Primiparous cows with SM presented a decrease in total
\end{abstract}

Recebido em 21 de setembro de 2014

Aceito em 19 de junho de 2015

*Autor para correspondência (corresponding author)

Email: lmolina@vet.ufmg.br 
milk yield when compared to primiparous cows without $S M(P<0.05)$. In contrast, the total milk yield of multiparous cows did not change. Differences in SCC, total yield and peak yield between the crossbreeding Holstein $x$ Zebu (HZ) levels were not observed $(P>0.05)$. SCC differed $(P<0.01)$ between drying off and immediate postpartum. Maintaining high environmental risk conditions in a dairy herd, housed in semi-intensive system, can reduce the variations in the occurrence of SM in summer and winter periods. This can also decrease the variations in SM occurrence between cows of different crossbreeding $H Z$ levels. In a herd characterized primarily by the presence of environmental mastitis, milk yield of primiparous cows with SCC above 200.000 cells/mL is reduced when compared to cows with SCC below 200.000 cells $/ \mathrm{mL}$. This finding was not observed for multiparous cows.

Keyword: somatic cell count, environmental mastitis, girolando, dairy cattle

\section{INTRODUÇÃO}

Aproximadamente $70 \%$ da produção de leite nacional provêm de vacas mestiças HolandêsZebu (HZ), fato este que pode ser parcialmente explicado pela maior adaptação desses animais às condições tropicais brasileiras, caracterizadas por um ambiente desafiador (estresse térmico, formação de barro, alta carga parasitária, entre outros) à expressão máxima do potencial genético desses animais, resultando, muitas vezes, em perda de eficiência no sistema de produção (Barbas, 2010). O sistema semiintensivo (SSI) é a forma de exploração leiteira mais frequentemente observada no Brasil Central. Caracteriza-se por vacas com produção média diária de oito a 17 litros de leite, mantidas em sistema de pastejo no período chuvoso e confinadas no período seco com fornecimento de alimentos suplementares no cocho, compreendendo atualmente $40 \%$ da produção nacional de leite (Olszensvski, 2011), ou seja, aproximadamente 14 bilhões de litros/ano. A alternância de ambiente característica do SSI, em virtude da sazonalidade na produção de forragem, pode resultar em uma manutenção de altas contagens de células somáticas (CCS) no rebanho, uma vez que fatores de risco observados no período chuvoso (acúmulo de barro) são substituídos em igual magnitude por outros no período seco (adensamento dos animais e acúmulo de matéria orgânica, principalmente de origem fecal), que resultam em maior exposição aos agentes potencialmente patogênicos para a glândula mamária (Hogan e Smith, 2003).

A mastite subclínica (MS) em vacas leiteiras representa um dos fatores que mais contribuem para perdas econômicas, acometendo de 20 a $50 \%$ das vacas em lactação (Pitkala et al., 2004). Aproximadamente $30 \%$ dos rebanhos brasileiros produzem leite com CCS de tanque acima de 600.000 cél./mL (Santos, 2013), o que, segundo Schwarz et al. (2010), indica alta prevalência de mastite subclínica no rebanho. Independentemente da duração do problema, esse resulta em perdas de produção de leite $\mathrm{e}$ alterações na composição e qualidade dele, devido ao processo inflamatório que ocorre na glândula mamária (Ivemeyer et al., 2011). Segundo Philpot (2002), estima-se que, para cada aumento de 100.000 cél./mL na CCS, acima do limite apresentado pela literatura $(200.000$ cél./mL - Harmon, 1994), ocorra uma perda de produção de leite de aproximadamente 2,5\%. Apesar de a adoção de certas medidas de manejo ser capaz de reduzir o número de infecções intramamárias (IIM) causadas por patógenos contagiosos, vários estudos têm demonstrado que a incidência de mastite causada por bactérias Gram-negativas se manteve constante ou aumentou nas últimas décadas (Hogan e Smith, 2003). Tendo em vista a relevância do tema para a produção leiteira e a escassez de trabalhos nacionais que apresentam o comportamento da MS ao longo da lactação de vacas com diferentes graus de sangue $\mathrm{HZ}$ em sistema semi-intensivo, o objetivo do presente trabalho foi avaliar o comportamento longitudinal da CCS e a influência da MS na produção de leite e no pico de produção de vacas mestiças de diferentes ordens de parto e graus de sangue HZ.

\section{MATERIAL E MÉTODOS}

Para realização do presente estudo, um rebanho comercial foi acompanhado durante 15 meses no município de Itaúna, MG. O rebanho era composto por animais 5/8 Holandês-Gir, 3/4 Holandês-Gir, 7/8 Holandês-Gir e 15/16 Holandês-Gir, com produção média de $16,5 \mathrm{~kg}$ de leite/dia, criados em sistema semi-intensivo. Por se tratar de um estudo longitudinal, ocorreu, ao 
longo do período, uma variação mensal no número dos animais em lactação, sendo o mínimo de 75 e o máximo de 183 . Os animais foram ordenhados duas vezes ao dia, com intervalo entre ordenhas de 12 horas, em equipamento mecânico $2 \times 4 \times 8$, sem mecanismo de extração automática de teteiras.

Para definição do perfil de patógenos causadores de mastite no rebanho, no início do período experimental foi realizada análise microbiológica de todos os animais em lactação. Os cultivos foram feitos segundo o padrão proposto pelo NMC (Laboratory..., 1999), sendo realizados três cultivos de cada vaca, com amostras de leite coletadas em intervalo de sete a 15 dias. Antes da coleta das amostras, foi realizado o descarte dos três primeiros jatos, com posterior desinfecção dos tetos com solução pré-dipping com cloro a $2 \%$. No momento da coleta, foi realizada antissepsia do esfíncter do teto, utilizando-se algodão umedecido em álcool a $70 \%$. Os jatos foram retirados de cada teto individualmente, formando amostras compostas de aproximadamente $50 \mathrm{~mL}$ cada uma. Elas foram acondicionadas em frascos estéreis e congeladas a $-20^{\circ} \mathrm{C}$ para posterior envio ao laboratório. As análises foram realizadas pelo Laboratório Tecsa ${ }^{\circledR}$, em Belo Horizonte, MG. Todas as amostras que apresentaram um ou dois microrganismos na cultura foram consideradas positivas, enquanto as amostras em que foi detectado crescimento de três ou mais patógenos foram consideradas como contaminadas e descartadas.

Durante o período de estudo, coletaram-se mensalmente amostras de leite compostas e individuais, destinadas à análise da CCS, iniciando-se no $10^{\circ}$ dia de lactação, segundo o protocolo do NMC (Laboratory..., 1999). As amostras foram retiradas diretamente de medidores de leite acoplados ao equipamento de ordenha e acondicionadas em frascos contendo dois comprimidos de bronopol (2-bromo-2nitropropano-1,3-diol), permitindo sua conservação à temperatura ambiente. As amostras foram homogeneizadas por inversão do frasco até a completa dissolução dos comprimidos e enviadas ao laboratório. As análises de CCS foram realizadas pelo método eletrônico em equipamento Bentley CombSystem ${ }^{\circledR} \quad 2300 \quad$ (Bentley Instruments Incorporated - Minneapolis, EUA).

O monitoramento da ocorrência de mastite subclínica foi realizado de forma individual, considerando portador aqueles animais com CCS $>200.000$ cél. $/ \mathrm{mL}$, de acordo com Harmon (1994). A ocorrência de mastite clínica foi determinada pelo teste da caneca telada, não sendo coletadas amostras para diagnóstico microbiológico desses casos. Em caso de diagnóstico de mastite clínica no dia da coleta de leite para CCS, a amostra não era coletada.

A produção de leite foi avaliada, semanalmente, durante as ordenhas da manhã e da tarde, sendo mensurada por meio de medidores de leite acoplados ao equipamento de ordenha, possibilitando, assim, a avaliação da produção diária individual dos animais (n). A CCS média ponderada do rebanho foi calculada pelo emprego da fórmula:

$\sum\left(\right.$ CCS animal $_{(\mathrm{n})} \times$ produção mensal de leite $\left.\operatorname{animal}_{(\mathrm{n})}\right)$ produção total de leite no mês

Os dados de dias em lactação das vacas (DEL), lactação total e ordem de parto foram registrados no software zootécnico da propriedade.

Para avaliar o efeito da CCS sobre a produção leiteira, as vacas foram divididas em dois grupos. O valor de corte para vacas sadias foi CCS $<200.000$ cél. $/ \mathrm{mL}$, e o valor de corte para vacas infectadas foi CCS $\geq 200.000$ cél./mL (Harmon, 1994). Os dados foram avaliados por análise de variância pelo PROC MIXED do programa estatístico SAS (Versão 9.1 para Windows. SAS Inst. Inc., Cary, NC.).

\section{RESULTADOS E DISCUSSÃO}

O resultado da cultura microbiológica de leite e a CCS em vacas primíparas e multíparas estão apresentados na Tab. 1. 
Tabela 1. Frequência de bactérias encontradas nos cultivos microbiológicos positivos de leite e média ponderada da contagem de células somáticas (CCS) de vacas primíparas e multíparas

\begin{tabular}{lcccccc} 
& \multicolumn{2}{c}{ Rebanho } & \multicolumn{2}{c}{ Primíparas } & \multicolumn{2}{c}{ Multíparas } \\
\cline { 2 - 7 } Mo & $\%$ & CCS (cél./mL) & $\%$ Amostras & CCS (cél./mL) & \% Amostras & CCS (cél./mL) \\
& Amostras & & & & & \\
& 6 & $620.000 \mathrm{AB}$ & 6,3 & $240.000 \mathrm{Aa}$ & 5 & $847.000 \mathrm{Aa}$ \\
Sta a & 31 & $275.000 \mathrm{~B}$ & 58,4 & $163.000 \mathrm{Ab}$ & 18 & $453.000 \mathrm{Aa}$ \\
SCN & 29 & $845.000 \mathrm{~A}$ & 8,3 & $1.758 .000 \mathrm{Aa}$ & 38,5 & $748.000 \mathrm{Aa}$ \\
CL & 34 & $1.100 .000 \mathrm{~A}$ & 27 & $856.000 \mathrm{Aa}$ & 38,5 & $1187.000 \mathrm{Aa}$ \\
Strep & &
\end{tabular}

Médias seguidas de letras distintas, maiúsculas nas colunas e minúsculas nas linhas, diferem estatisticamente pelo teste de Tukey $(\mathrm{P}<0,05)$. Mo: microrganismo; Sta a: Staphylococcus aureus; SCN: Staphylococcus coagulase negativa; CL: células leveduriformes; Strep: Streptococcus ambientais

Entre as amostras que resultaram em culturas positivas, os patógenos encontrados foram Streptococcus ambientais (Strep), células leveduriformes (CL), Staphylococcus coagulase negativa (SCN) e Staphylococcus aureus (Sta a), sendo observada grande proximidade das porcentagens de amostras positivas para SCN (31\%), CL (29\%) e Strep (34\%). Apenas 6\% das amostras positivas apresentaram Sta a. Os patógenos ambientais Strep e as CL foram os principais encontrados (63\%), seguidos por microrganismos oportunistas (SCN) e, por último, os agentes classificados como contagiosos (Sta a). Ao se estratificar a frequência dos agentes isolados no cultivo microbiológico das vacas primíparas e multíparas, observa-se que, nas primíparas, a infecção por SCN foi predominante $(58,4 \%)$, seguida pela infecção por Strep (27\%). Nas vacas multíparas, houve predominância da infecção por patógenos ambientais, com equivalência nas porcentagens de amostras positivas para CL e Strep $(38,5 \%)$. Em ambos os grupos, Sta a foi o patógeno menos observado.

A literatura relaciona alta CCS do tanque de leite à presença de patógenos contagiosos no rebanho (Oliveira, 2013). Entretanto, rebanhos com baixa prevalência de patógenos contagiosos, como identificado neste estudo (Sta a 6\%), passam a apresentar possíveis problemas relacionados à saúde de úbere em decorrência da atuação de patógenos ambientais (Jones e Swisher, 1998; Green et al., 2007; Gentilini et al., 2012; Maia et al., 2013). Vacas infectadas com microrganismos ambientais apresentaram alta CCS $(1100.000 \mathrm{e}$ 845.000, para Strep e CL, respectivamente), sendo tais valores superiores à $\mathrm{CCS}$ das vacas positivas para $\mathrm{SCN}(\mathrm{P}<0,05)$, entretanto sem diferirem da CCS das amostras positivas para Sta a. Com exceção da CCS das amostras positivas para $\mathrm{SCN}$, que foi menor nas vacas primíparas (163.000) quando comparadas às multíparas (453.000) $(\mathrm{P}<0,05)$, a CCS média não diferiu entre as ordens de parto, independentemente dos patógenos encontrados em cada amostra. Scaccabarozzi et al. (2011) relacionam a alta prevalência de CL ao esterco acumulado no ambiente das vacas e à dieta empregada, fatos esses que podem estar associados a tal achado no presente estudo, uma vez que foi observado grande acúmulo de matéria orgânica no ambiente em que os animais eram mantidos, além da utilização de dieta total, tendo como base forrageira a cana-de-açúcar, dieta na qual tipicamente se encontram leveduras.

Associado ao resultado microbiológico, pode-se observar o comportamento longitudinal da CCS no período avaliado (Tab. 2). Ao longo dos meses de observação, a CCS média ponderada variou entre média $(255.000$ cél. $/ \mathrm{mL})$ e muito alta (975.000 cél./mL), segundo classificação apresentada por Barkema et al. (1998), valores esses resultantes das oscilações na prevalência de MS no rebanho.

Esses resultados denotam um comportamento flutuante da CCS ao longo do ano, condizente com a dinâmica da infecção por patógenos ambientais. No período seco do primeiro ano (maio-out.), a CCS oscilou em torno de 337.500 cél. $/ \mathrm{mL}$, sendo observada também menor prevalência de MS (24\%) no mês de maio. No período chuvoso subsequente (nov.-abr.), observou-se elevação da CCS do rebanho (595.400 cél. $/ \mathrm{mL})$, com a maior prevalência de MS (60\%), identificada no mês de abril, seguida novamente por uma diminuição da CCS para 448.750 cél. $/ \mathrm{mL}$ no período seco subsequente. $\mathrm{O}$ rebanho apresentou uma prevalência média de $42 \%$ de animais com MS. Em outros estudos em 
que os principais patógenos isolados foram os microrganismos ambientais (Todhunter et al., 1995; Jones e Swisher, 1998), os autores também encontraram prevalência de MS variando entre $40 \%$ e 50\%. Embora Jones e Swisher (1998) afirmem que de $40 \%$ a $45 \%$ das mastites em rebanhos com CCS abaixo de 200.000 a 300.000 cél./mL são causadas por patógenos ambientais (coliformes e estreptococos), no presente estudo, a CCS média de tanque no período experimental foi de 454.000 cél. $/ \mathrm{mL}$. Possivelmente, esses achados possam ser explicados pela dinâmica de infecção dos patógenos ambientais, que é de curta duração (Todhunter et al., 1995), somada ao desafio ambiental constante, bem como pela alta taxa de cura espontânea associada a uma alta taxa de novas infecções, em decorrência principalmente da constante exposição do úbere a ambientes propícios à infecção por microrganismos ambientais, resultando, assim, na manutenção da CCS de tanque acima da média apresentada pela literatura. Como apresentado por Zehner et al. (1986), o crescimento e a manutenção dos microrganismos ambientais dependem das condições favoráveis de alta temperatura, umidade e acúmulo de matéria orgânica, fatores esses presentes na maioria dos sistemas semi-intensivos de exploração pecuária, o que leva a uma manutenção da CCS do rebanho em valores acima de 380.000 cél./mL no período seco.

Tabela 2. Variação mensal da contagem de células somáticas (CCS) e da frequência de animais com mastite subclínica no rebanho

\begin{tabular}{cccccc} 
& & & \multicolumn{3}{c}{$\begin{array}{c}\text { Frequência de mastite subclínica } \\
(\text { CCS } \geq 200.000 \text { cél./mL) }(\%)\end{array}$} \\
\cline { 4 - 5 } Mês & \multirow{2}{*}{$N^{\circ}$ de animais } & CCS (cél./mL) & Rebanho & Primíparas & Multíparas \\
\cline { 4 - 6 } Maio & 93 & 255.000 & 24 & 36,4 & 63,6 \\
Jun. & 99 & 397.000 & 37 & 43,2 & 56,8 \\
Jul. & 108 & 313.000 & 38 & 41,5 & 58,5 \\
Ago. & 111 & 348.000 & 41 & 45,7 & 54,3 \\
Set. & 91 & 354.000 & 37 & 56,7 & 43,3 \\
Out. & 75 & 358.000 & 36 & 52,0 & 48,0 \\
Nov. & 83 & 561.000 & 40 & 33,3 & 66,7 \\
Dez. & 94 & 460.000 & 43 & 32,5 & 67,5 \\
Jan. & 121 & 469.000 & 41 & 26,0 & 74,0 \\
Mar. & 122 & 512.000 & 46 & 26,8 & 73,2 \\
Abr. & 146 & 975.000 & 60 & 19,3 & 80,7 \\
Maio & 149 & 398.000 & 46 & 10,0 & 90,0 \\
Jun. & 170 & 693.000 & 58 & 15,3 & 84,7 \\
Jul. & 183 & 477.000 & 46 & 14,0 & 86,0 \\
Set. & 125 & 227.000 & 30 & 8,0 & 92,0 \\
\hline Média & 118 & 454.000 & 42 & 31 & 69 \\
\hline
\end{tabular}

Muitos pesquisadores, sobretudo de países do hemisfério norte cujas condições ambientais diferem das encontradas no Brasil Central, relatam que as infecções por germes ambientais apresentam elevações bem marcadas na CCS no período chuvoso e quente (Riekerink et al., 2007), acompanhadas de intensas quedas nesses valores à medida que a estação seca e fria vai progredindo. Entretanto, nas condições ambientais características dos sistemas semiintensivos de exploração leiteira no Brasil Central, a mudança das estações leva a uma substituição dos fatores de risco para mastite ambiental, e não a sua diminuição. $\mathrm{O}$ ambiente com muito barro (no período chuvoso) é substituído pelo acúmulo de matéria orgânica e, consequentemente, pelo aumento da umidade no ambiente durante o período seco. Somada a isso, muitas vezes a temperatura ambiental permanece satisfatória ao crescimento microbiano, favorecendo, assim, a manutenção de um ambiente propício à disseminação dos germes ambientais ao longo do ano, independentemente da estação climática. Tais fatos podem resultar na permanência de uma alta CCS durante a maior parte do ano, 
independentemente da estação climática, como observado no presente estudo: CCS média 589.000 cél. $/ \mathrm{mL}$ no verão e 481.000 cél. $/ \mathrm{mL}$ no inverno $(\mathrm{P}>0,05)$. Reis et al. (2011), em experimento realizado no Sudeste brasileiro, não encontraram diferença entre CCS no verão e no inverno, apesar de trabalharem com um valor médio inferior ao observado neste estudo. De forma semelhante, individualmente, as vacas primíparas e multíparas também apresentaram oscilações na porcentagem de animais com MS ao longo dos meses. De maneira geral, ao longo do período estudado, as multíparas apresentaram maior prevalência de animais com MS (69\%) em comparação às primíparas $(31 \%)$. Essa diferença anteriormente apresentada sobre a prevalência da MS nas diferentes ordens de parto também é evidenciada quando se avalia a CCS média por ordem de parição. Na Tab. 3, estão apresentadas a CCS e a produção de leite na lactação e no pico de produção em vacas primíparas e multíparas. As multíparas apresentaram valores de CCS superiores às primíparas, sendo $672.000 \mathrm{e}$ 398.000 cél. $/ \mathrm{mL}$, respectivamente $(\mathrm{P}<0,05)$.

Tabela 3. Ordem de parto, contagem de células somáticas (CCS), produção total e pico de produção de leite

\begin{tabular}{cccc}
\hline Ordem de parto & CCS $($ cél. $/ \mathrm{mL})$ & Produção total de leite $(\mathrm{kg})$ & Pico de produção $(\mathrm{kg})$ \\
\hline Primípara & $398.000 \mathrm{~b}$ & $4.918 \mathrm{~b}$ & $21,15 \mathrm{~b}$ \\
Multípara & $672.000 \mathrm{a}$ & $5.640 \mathrm{a}$ & $25,75 \mathrm{a}$ \\
\hline
\end{tabular}

Médias seguidas de letras distintas na coluna diferem estatisticamente pelo teste $\mathrm{t}(\mathrm{P}<0,05)$.

Quist et al. (2008) destacam a maior susceptibilidade dos animais mais velhos à MS. Apesar de as novilhas apresentarem elevados valores de CCS, a diferença entre CCS de vacas e novilhas pode ser explicada, pelo menos em parte, pelo menor tempo de permanência das primíparas no sistema de produção, fazendo com que essas sejam menos expostas aos fatores de risco para mastite. O mesmo resultado é observado para lactação total (Nutrient..., 2001) e pico de produção. Hass et al. (2004) e Berry et al. (2007) relatam a maior susceptibilidade das multíparas à mastite, assim como o maior tempo de duração das infecções nesses animais, o que pode resultar em maior destruição do tecido secretor, levando à maior CCS média e à produção de leite proporcionalmente menor, quando comparadas às primíparas. Nordlund e Cook (2004) relatam que novilhas devem apresentar no pico de produção $75 \%$ da produção de leite das vacas na mesma fase para que se classifique como uma boa produção de leite. Ressalta-se que, apesar de a produção total de leite ter sido maior nas multíparas, no presente estudo, as primíparas apresentaram $82,1 \%$ da produção de leite, no pico de lactação, indicando aumento do potencial produtivo das primíparas em relação às vacas do rebanho.

Não foram observadas diferenças entre a CCS, a produção total e o pico de produção de leite durante a lactação nos diferentes graus de sangue HZ, como apresentado na Tab. 4.

Tabela 4. Grau de sangue em diferentes cruzamentos Holandês x Zebu (HZ), contagem de células somáticas (CCS), produção total e pico de produção de leite

\begin{tabular}{cccc}
\hline Grau de sangue & CCS $($ cél. $/ \mathrm{mL})$ & Produção total de leite $(\mathrm{kg})$ & Pico de produção $(\mathrm{kg})$ \\
\hline $5 / 8 \mathrm{HZ}$ & $600.000 \mathrm{a}$ & $5.302 \mathrm{a}$ & $24,6 \mathrm{a}$ \\
$3 / 4 \mathrm{HZ}$ & $630.000 \mathrm{a}$ & $5.264 \mathrm{a}$ & $23,5 \mathrm{a}$ \\
$7 / 8 \mathrm{HZ}$ & $628.000 \mathrm{a}$ & $5.006 \mathrm{a}$ & $22,4 \mathrm{a}$ \\
$15 / 16 \mathrm{HZ}$ & $616.000 \mathrm{a}$ & $5.545 \mathrm{a}$ & $23,2 \mathrm{a}$ \\
\hline
\end{tabular}

Médias seguidas de letras distintas na coluna diferem estatisticamente pelo teste $\mathrm{t}(\mathrm{P}<0,05)$.

Apesar da inexistência de estudos que analisam o perfil de CCS entre os vários cruzamentos HZ, sabe-se que há diferença entre raças quanto à susceptibilidade à mastite (De Vliegher et al., 2004), sendo a raça Holandesa a mais susceptível
(Berry et al., 2007, Ivemeyer et al., 2011). Entretanto, segundo Haskell et al. (2009), os valores da CCS estão mais associados às práticas de manejo do que à genética, uma vez que a herdabilidade para essa característica é baixa 
(Heringstad et al., 2008). No presente trabalho, o fato de os animais estarem sob o mesmo manejo e expostos a um alto desafio ambiental pode explicar, como sugerido por Haskell et al. (2009), a alta CCS nos diferentes grupamentos genéticos e a ausência de diferença observada neste parâmetro, bem como na produção total e no pico de produção de leite observada.

A produção total de leite em vacas sem MS e com MS, independentemente do grau de sangue e da ordem de parto, foi superior no grupo sadio $(\mathrm{P}<0,01)$ (Tab. 5).

Tabela 5. Efeito da contagem de células somáticas (CCS) sobre a produção total de leite de vacas primíparas e multíparas e o pico de produção

\begin{tabular}{ccccc}
\multirow{2}{*}{$\begin{array}{c}\mathrm{CCS} \\
(\text { cél. } / \mathrm{mL})\end{array}$} & \multicolumn{3}{c}{ Produção total de leite $(\mathrm{kg})$} & \multirow{2}{*}{ Pico de produção de leite $(\mathrm{kg})$} \\
\cline { 2 - 4 } & Rebanho & Primíparas & Multíparas & \\
\hline 200.000 & $5.509 \mathrm{~A}^{*}$ & $5.324 \mathrm{Aa}$ & $5.692 \mathrm{Aa}$ & $23,5 \mathrm{a}$ \\
$\geq 200.000$ & $5.049 \mathrm{~B}^{*}$ & $4.510 \mathrm{Bb}$ & $5.588 \mathrm{Aa}$ & $23,4 \mathrm{a}$
\end{tabular}

Médias seguidas de letras distintas, maiúsculas na coluna e minúsculas na linha, diferem estatisticamente pelo teste $\mathrm{t}$ $(\mathrm{P}<0,05) ;(\mathrm{P}<0,01)^{*}$.

Vacas primíparas com MS apresentaram uma redução da produção total de leite quando comparadas às vacas primíparas sem MS $(\mathrm{P}<0,05)$. Em contraste, a produção total de leite das vacas multíparas não foi alterada, independentemente da CCS. Analisando de forma semelhante, Hagnestam-Nielsen et al. (2009) encontraram uma redução na produção de leite de $155 \mathrm{~kg}$ de leite na lactação total de primíparas e de $455 \mathrm{~kg}$ para vacas multíparas com e sem MS. No presente trabalho, essa perda em primíparas foi de $814 \mathrm{~kg}$ de leite quando comparada à perda em animais sadios $(\mathrm{P}<0,05) \mathrm{e}$ de $104 \mathrm{~kg}$ de leite no grupo de multíparas portadoras de MS, comparadas às sadias $(\mathrm{P}>0,05)$.

Ao se avaliar a produção de leite total entre grupos de ordem de parto, com ou sem MS, observou-se produção semelhante entre primíparas e multíparas sem MS. O mesmo fato não ocorreu ao se compararem multíparas e primíparas com MS, sendo a produção total das multíparas superior $(\mathrm{P}<0,05)$. A CCS não influenciou o pico de produção de leite deste rebanho.

A CCS das vacas em lactação diferiu $(\mathrm{P}<0,01)$ entre o período de secagem (320 DEL médio) (778.000) e a primeira coleta pós-parto (27 DEL médio) (438.000) (Tab. 6).
Tabela 6. Média da contagem de células somáticas (CCS) e dos dias em lactação (DEL) no momento da secagem e no primeiro teste após o parto

\begin{tabular}{lcc}
\hline $\begin{array}{c}\text { Momento da } \\
\text { coleta }\end{array}$ & DEL (dias) & $\begin{array}{c}\text { CCS média } \\
\text { (cél./mL) }\end{array}$ \\
\hline Secagem & 320 & $778.000 \mathrm{a}$ \\
$1^{\circ}$ teste pós-parto & 27 & $438.000 \mathrm{~b}$ \\
\hline
\end{tabular}

Médias seguidas de letras distintas diferem estatisticamente pelo teste $\mathrm{t}(\mathrm{P}<0,01)$.

A diminuição da CCS ocorrida entre a secagem e o primeiro teste pós-parto certamente está associada à terapia de vaca seca, que foi empregada em todas as vacas. Entretanto, em ambos os momentos, mesmo considerando a redução, a CCS observada se encontrava acima de 200.000 cél./mL (Harmon, 1994), caracterizando a ocorrência de MS. Segundo Bradley et al. (2010), o uso de antibioticoterapia para vacas secas em multíparas é um modo efetivo de se reduzir a ocorrência de novas infecções por patógenos ambientais, principalmente Strep, e aumentar a taxa de cura de infecções preexistentes de SCN e Sta a, diminuindo, assim, as taxas de mastite clínica e a CCS nos primeiros 30 dias de lactação desses animais. Apesar da diminuição anteriormente apresentada, a manutenção dos valores médios da CCS acima dos valores preconizados por Harmon (1994) pode estar associada a: novas infecções ocorridas no pré-parto imediato, 
decorrentes da baixa concentração do antibiótico presente na glândula mamária ao final do período seco (Bradley e Green, 2001); novas infecções por coliformes, uma vez que esses apresentam maior resistência à terapia de vaca seca quando comparados aos demais germes (Bradley et al., 2010; Maia et al., 2013) ou à contaminação da glândula entre o parto e a primeira coleta de leite para análise de CCS, no período pós-parto imediato, período esse considerado por Hogan e Smith (2003) como de alta susceptibilidade a novas infecções intramamárias causadas principalmente por patógenos ambientais

\section{CONCLUSÕES}

A manutenção das condições de elevado risco ambiental em rebanho leiteiro manejado em sistema semi-intensivo pode minimizar as variações na ocorrência de mastite subclínica nos períodos de verão e inverno, assim como na expressão do problema em vacas de diferentes graus de sangue Holandês-Zebu. Em um rebanho caracterizado pela ocorrência de mastite predominantemente ambiental, a produção de leite na lactação total de vacas primíparas com CCS superior a 200.000 cél. $/ \mathrm{mL}$ é reduzida em comparação com vacas com CCS inferior a 200.000 cél. $/ \mathrm{mL}$, o que não foi observado em vacas multíparas.

\section{REFERÊNCIAS}

BARBAS, C.C. Produtividade de vacas mestiças leiteiras em sistema semi-intensivo nos municípios de Irituia e Mãe do Rio do nordeste paraense. 2010. 25f. Dissertação (Mestrado em Ciência Animal) - Núcleo de Ciências Agrárias e Desenvolvimento Rural, Universidade Federal do Pará, Belém, PA.

BARKEMA, H.W.; SCHUKKEN, Y.H.; LAM, T.J. et al. Incidence of clinical mastitis in dairy herds grouped in three categories by bulk milk somatic cell counts. J. Dairy Sci., v.81, p.411419, 1998.

BERRY, D.P.; LEE, J.M.; MACDONALD, K.A. et al. Associations among body condition score, body weight, somatic cell count, and clinical mastitis in seasonally calving dairy cattle. $J$. Dairy Sci., v.90, p.637-648, 2007.
BRADLEY, A.J.; BREEN, J.E.; PAYNE, B. et $a l$. The use of a cephalonium containing dry cow therapy and an internal teat sealant, both alone and in combination. J. Dairy Sci., v.93, p.15661577, 2010.

BRADLEY, A.J.; GREEN, M.J. The importance of nonlactating period in the epidemiology of intramammary infection and strategies for prevention. Vet. Clin. North Am. Food Anim. Pract., v.20, p.547-568, 2004.

DE VLIEGHER, S.; BARKEMA, H.W.; STRYHN, H. et al. Impact of early lactation somatic cell count in heifers on somatic cell counts over the first lactation. J. Dairy Sci., v.87, p.3672-3682, 2004.

GENTILINI, M.B.; MOLINA, L.R.; CARVALHO, A.U. Vacinação com Escherichia coli J5 no pré-parto e ocorrência de mastite e produção de leite de vacas mestiças leiteiras. Arq. Bras. Med. Vet. Zootec., v.65, p.1367-1375, 2013.

GREEN, M.J.; BRADLEY, A.J.; MEDLEY, G.F. et al. Cow, farm, and management factors during the dry period that determine the rate of clinical mastitis after calving. J. Dairy Sci., v.90, p.3764-3776. 2007.

HAAS, Y.; VEERKAMP, R.F.; BARKEMA, H.W. et al. Associations between pathogenspecific cases of clinical mastitis and somatic cell count patterns. J. Dairy Sci., v.87, p.95-105, 2004.

HAGNESTAM-NIELSEN, C.; EMANUELSON, U.; BERGLUND, B.; STRANDBERG, E. Relationship between somatic cell count and milk yield in different stages of lactation. J. Dairy Sci., v.92, p.3124-3133, 2009.

HARMON, R.J. Physiology of mastitis and factors affecting somatic cell counts. J. Dairy Sci., v.77, p.2103-2112, 1994.

HASKELL, M.J.; LANGFORD, F.M.; JACK, M.C. et al. The effect of organic status and management practices on somatic cell counts on UK dairy farms. J. Dairy Sci., v.92, p.37753780, 2009.

HERINGSTAD, B.; SEHESTED, E.; STEINE, T. Correlated selection responses in somatic cell count from selection against clinical mastitis: short communication. J. Dairy Sci., v.91, p.44374439, 2008. 
HOGAN, J.; SMITH, K.L. Coliform mastitis. Vet. Res., v.34, p.507-519, 2003.

IVEMEYER, S.; KNIERIM, U.; WAIBLINGER, S. Effect of human-animal relationship and management on udder health in Swiss dairy herds. J. Dairy Sci., v.94, p.5890-5902, 2011.

JONES, G.M.; SWISHER, J.M. Environmental streptococcal and coliform mastitis. Virginia: Virginia State University, 1998. (Virginia Cooperative Extension).

LABORATORY handbook on bovine mastitis. Madison National Masttitis Council, 1999. 222p.

MAIA, P.V.; MOLINA, L.R.; FACURY FILHO, E.J. et al. Vacinação com Escherichia coli J5 no pré-parto e ocorrência de mastite e produção de leite de vacas mestiças leiteiras. Arq. Bras. Med. Vet. Zootec., v.65, p.1367-1375, 2013.

NORDLUND, K.V.; COOK, N.B. Using herd records to monitor transition cow survival, productivity, and health. Vet. Clin. North Am. Pract., v.20, p.627-649, 2004.

NUTRIENT requirements of dairy cattle: 7 ed. Washington: National Research Council, 2001. 408 p.

OLIVEIRA, E.F. Análise espacial da contagem de células somáticas e prevalência de patógenos contagiosos da mastite em rebanhos leiteiros em Minas Gerais, Brasil. 2013. 35f. Dissertação (Mestrado profissional em Ciência e Tecnologia de Leite e Derivados) - Universidade Federal de Juiz de Fora, Juiz de Fora, MG.

OLSZENSVSKI, F.T. Avaliação do ciclo de vida da produção de leite em sistema sem extensivo e intensivo: Estudo aplicado. 2011. 99f. Dissertação (Mestrado em Engenharia Ambiental) - Universidade Federal de Santa Catarina, Florianópolis, SC.

PHILPOT, W.N. Qualidade do leite e controle de mastite: passado, presente e futuro. In: CONGRESSO PANAMERICANO DE QUALIDADE DO LEITE E CONTROLE DE MASTITE, 2., 2002, Ribeirão Preto. Anais... São Paulo: Instituto Fernando Costa, 2002. p.23-38.
PITKALA, A.; HAVERI, M.; PYORALA, S. et al. Bovine mastitis in Finland 2001 - Prevalence, distribution of bacteria, and antimicrobial resistance. J. Dairy Sci., v.87, p.2433-2441, 2004.

QUIST, M.A.; LEBLANC, S.J.; HAND, K.J. et al. Milking-to-milking variability for milk yield, fat and protein percentage, and somatic cell count. J. Dairy Sci., v.91, p.3412-3423, 2008.

REIS, C.B.M.; BARREIRO, J.R.; MORENO, J.F. et al. Evaluation of somatic cell count thresholds to detect subclinical mastitis in Gyr cows. J. Dairy Sci., v.94, p.4406-4412, 2011.

RIEKERINK, R.G.O.; BARKEMA, H.W.; STRYHN, H. The effect of season on somatic cell count and the incidence of clinical mastitis. J. Dairy Sci., v.90, p.1704-1715, 2007.

SANTOS, M.S. CCS muito baixa: problema ou solução? Rio Grande do Sul: Inforleite, 2013. Disponível em: <http:/qualileite.org/pdf/CCSalta.pdf $>$. Acessado em: 20 ago. 2013.

SCACCABAROZZI, L.; LOCATELLI, C.; PISONI, G. et al. Epidemiology and genotyping of Candida rugosa strains responsible for persistent intramammary infections in dairy cows: short communication. J. Dairy Sci., v.94, p.4574-4577, 2011.

SCHWARZ, D.; DIESTERBECK, U.S.; FAILING, K. et al. Somatic cell counts and bacteriological status in quarter foremilk samples of cows in Hesse, Germany - a longitudinal study. J. Dairy Sci., v.93, p.5716-5728, 2010.

STATISTICAL Analisys System for windows.Versão 9.1. Cary: SAS Inst. Inc., 2004. TODHUNTER, D.A.; SMITH, K.L.; HOGAN, J.S. Environmental streptococcal intramammary infections of the bovine mammary gland. $J$. Dairy Sci., v.78, p.2366-2374, 1995.

ZEHNER, M.M.; FARNSWORTH, R.J.; APPLEMAN, R.D. et al. Growth of environmental mastitis pathogens in various bedding materials. J. Dairy Sci., v.69, p.19321941, 1986. 